University of Nebraska - Lincoln

DigitalCommons@University of Nebraska - Lincoln

November 2004

\title{
Executive function in preschool children: Examination through everyday behavior
}

\author{
P. K. Isquith \\ Dartmouth Medical School, Isquith@Dartmouth.edu \\ G. Gioia \\ K. A. Espy \\ University of Nebraska-Lincoln, kespy2@unl.edu
}

Follow this and additional works at: https://digitalcommons.unl.edu/dcnlfacpub

Part of the Neurosciences Commons

Isquith, P. K.; Gioia, G.; and Espy, K. A., "Executive function in preschool children: Examination through everyday behavior" (2004). Developmental Cognitive Neuroscience Laboratory - Faculty and Staff Publications. 9.

https://digitalcommons.unl.edu/dcnlfacpub/9

This Article is brought to you for free and open access by the Developmental Cognitive Neuroscience Laboratory at DigitalCommons@University of Nebraska - Lincoln. It has been accepted for inclusion in Developmental Cognitive Neuroscience Laboratory - Faculty and Staff Publications by an authorized administrator of DigitalCommons@University of Nebraska - Lincoln. 


\title{
Executive Function in Preschool Children: Examination Through Everyday Behavior
}

\author{
Peter K. Isquith \\ Department of Psychiatry \\ Dartmouth Hitchcock Medical School
}

\author{
Gerard A. Gioia \\ Pediatric Neuropsychology Program \\ Center for Neurosciences and Behavioral Medicine \\ Children's National Medical Center, Washington, DC \\ Kimberly Andrews Espy \\ Department of Family and Community Medicine \\ Southern Illinois University School of Medicine
}

\begin{abstract}
Clinical assessment of executive function in preschool-age children is challenging given limited availability of standardized tasks and preschoolers' variable ability to participate in lengthy formal evaluation procedures. Given the benefits of ecological validity of measuring behavior by rating scales, the Behavior Rating Inventory of Executive Function (Gioia, Isquith, Guy, \& Kenworthy, 2000) was modified for use with children ages 2 through 5 years to assess executive functions in an everyday context. The scale development process, based on samples of 460 parents and 302 teachers, yielded a single 63 -item measure with 5 related, but nonoverlapping, scales, with good internal consistency and temporal stability. Exploratory factor analyses identified 3 consistent factors: Emergent Metacognition, Flexibility, and Inhibitory Self-Control across parent and teacher samples. In a second study with a mixed sample of preschool children with various developmental disorders, parents and teachers rated these preschool children as having greater executive difficulties in most domains than matched controls. Such rating-scale methodology may be a useful complementary tool by which to reliably assess executive functions in preschool children via everyday behaviors in the natural environment.
\end{abstract}

Requests for reprints should be sent to Peter K. Isquith, Department of Psychiatry, Dartmouth Hitchcock Medical School, One Medical Center Dr., Lebanon, NH 03756-0001. E-mail: peter.k.isquith@dartmouth.edu 
Although the development of executive functions in children has become an active topic of discussion and research over the past 2 decades (e.g., Fletcher et al., 1996; Passler, Isaac, \& Hynd, 1985; Welsh, Pennington, \& Grossier, 1991), less attention has been devoted to the structure, organization, and development of executive functions in infants and preschool-age children (Espy \& Kaufmann, 2002). One prominent view of preschooler's behavior is that young children are not able to exert higher order control of pertinent cognitive processes, emotional responses, and behavioral impulses. Historically, they are perceived as lacking inhibitory control, exhibiting significant distractibility, being inflexible in their ability to solve problems, and not organizing, planning, or monitoring their problem-solving behaviors. This "dysexecutive" behavior suggests that the study of executive functions in preschool-age children may not be particularly fruitful given the potential for a broad range of normal variability in these functions. However, the developmentally oriented neuropsychologist, whether focused on clinical service delivery or research investigation, has an inherent interest in the earliest roots of disorders that are evident in later childhood and adolescence. Through the study of the executive functions in preschoolers, the earliest forms or precursors of executive regulation can be defined and described. For example, better understanding of the roots of poor inhibitory control, later manifested in attention deficit hyperactivity disorder (ADHD), has potential implications for early detection and intervention of this disorder. Furthermore, a variety of disorders involving executive dysfunction, such as ADHD, autism spectrum disorders (ASD), and prematurity, may first manifest in the preschool years. Other acquired injuries, such as traumatic brain injury (TBI; see Ewing-Cobbs et al., this issue), when incurred in this age range may have greater or different impact on outcome than when such injuries are sustained later in life. Better characterization of this dysfunction at the earliest point of diagnosis is critical to a full understanding of the disorder, and it also can lead to important early interventions. The purpose of this article is to examine the potential for the assessment of executive function as manifested in the everyday behavior of preschool-age children, based on the premise that measurement of executive functions is possible when a developmentally appropriate behavioral repertoire is sampled (Wellman, 1988). We employed parental and teacher ratings of everyday behaviors that preschoolers display to explore the putative regulatory control of behavior, emotion, and cognitive problem-solving in this age range.

The development of attentional control, future-oriented, intentional problem solving, and self-regulation of emotion and behavior is considered to begin in infancy (Diamond, 1985; Haith, Hazan, \& Goodman, 1988) and continues into the preschool period (Espy, Kaufmann, McDiarmid, \& Glisky, 1999; Welsh, Pennington, \& Grossier, 1991). For example, early manifestations of executive functions, such as goal-directed, planful problem-solving behaviors in infants, have been demonstrated with the use of object permanence and object retrieval paradigms 
(Diamond, 1985, 1990). In toddlers, executive self-control abilities, such as maintaining an intentional action and inhibiting behavior incompatible with attaining a goal, undergo active development (Kochanska, Murray, \& Coy, 1997; Vaughn, Kopp, \& Krakow, 1984). Thus, early intentional self-control behaviors are present in infants and toddlers and contribute to goal-directed problem solving. Executive self-control at these early ages is, however, variable, fragile, and bound to the external stimulus situation, with increasing stability achieved between 18 and 30 months of age (Ruff \& Rothbart, 1996).

In preschool-age children, executive functions can be differentiated by using developmentally appropriate tasks, such as those adapted from developmental cognitive neuroscience. For example, working memory, flexibility, and inhibition skills can be discriminated in preschool children (Espy, Kaufmann, McDiarmid, et al., 1999; Hughes, 1998). Furthermore, the developmental trajectories of these executive functions differ (Espy, 1997; Espy, Kaufmann, McDiarmid, \& Glisky, 2001). Fundamental executive functions, such as inhibition and working memory, develop earlier, whereas the more complex processes, such as systematic problem solving and planning, have a more protracted course (Espy, 1997; Espy et al., 2001). As is the case with most dimensions of psychological and neuropsychological development, the emergence and development of executive control functions likely varies across individuals in terms of the age of onset, the rate of development, the level of proficiency at any given age, and the shape of the trajectory of skill acquisition. There is growing evidence that different neurological and behavioral disorders in preschoolers result in unique patterns of executive function disturbance (Diamond, Prevor, Callendar, \& Druin, 1997; Espy, Kaufmann, \& Glisky, 1999; Espy et al., 2003; Grodzinsky \& Diamond, 1992; McEvoy, Rogers, \& Pennington, 1993), such as is found in school-age children and adolescents (Gioia, Isquith, Kenworthy, \& Barton, 2002; Ozonoff \& Jensen, 1999; Pennington \& Ozonoff, 1996; Sergeant, Guerts, \& Oosterlaan, 2002).

Historically, clinical assessment of the executive functions in any age group has been challenging because of their fluid, dynamic nature (Denckla, 1994). This problem is particularly acute in preschool children (Espy \& Kaufmann, 2001), in part because of the variable nature of behavior and limitations in motor and verbal proficiency in this age range. Aside from the NEPSY Developmental Neuropsychological Assessment (NEPSY; Korkman, Kirk, \& Kemp, 1998) attention-executive subtests, there are few validated, standardized measures of executive function designed for this age group, limiting ease of clinical assessment and comparison across studies (Espy \& Kaufmann, 2001). The structured nature of the typical individual assessment situation, be it for clinical or research purposes, also may limit opportunities for observing executive functions, regardless of the age of the child tested (Silver, 2000). Nevertheless, active development of new perfor- 
mance measures of executive function specific to this age group is underway (e.g., Diamond et al., 1997; Espy et al., 2001).

Examination of everyday behavior is a complementary approach to assessing executive functions in preschool children. The child's everyday environments, both at home and at school or day care, are important venues for observing routine manifestations of the executive functions. This methodology recently has been employed in the measurement of executive function in school-age children and adolescents with the development of the Behavior Rating Inventory of Executive Function (BRIEF; Gioia, Isquith, Guy, \& Kenworthy, 2000). The BRIEF is a parent- and teacher-completed rating scale with 86 items in eight, nonoverlapping, scales tapping eight theoretically-derived subdomains of executive function as observed through everyday behaviors in children ages 5 to 18 years. The individual scales form two broad factor-based indexes: Inhibit, Shift, and Emotional Control scales compose a Behavioral Regulation Index, whereas Initiate, Working Memory, Plan/Organize, Organization of Materials, and Monitor scales form a Metacognition Index. Studies to date suggest that the BRIEF exhibits appropriate internal consistency, temporal stability, and evidence of validity based on convergence or divergence with a variety of measures and on internal factor structure (Gioia et al., 2000). The instrument also captures profiles of executive functions that differ across common developmental and acquired disorders, including ADHD, ASD, TBI, and reading disorders (Gioia et al., 2002). Finally, it has been argued that such rating-scale methodology adds a complementary ecological validity dimension to clinical assessment of executive function (Gioia \& Isquith, in press; Silver, 2000). Reliable reports of the child's everyday behavioral manifestations of executive dysfunction allow for a high degree of ecological validity in understanding their real-world needs relative to test performance in an office setting. On the other hand, rating scales have their own limitations in terms of providing a more global level of behavior and less process-specific information. Rater bias can influence the ratings, particularly if the parent or teacher has certain unreasonable expectations for the child's behavior. Nevertheless, capitalizing on parents and teachers as valuable sources of data high in ecological validity, we explored modification and application of the BRIEF for assessing executive functions in preschool-age children.

In consultation with colleagues in pediatric neuropsychology regarding executive function domains that might be assessed behaviorally in preschoolers, the consensus was that behavioral and emotional regulation would be relatively clear and measurable, but the more metacognitive aspects of executive function, such as planning, organizing, initiating, monitoring, and working memory, in preschoolers might be more difficult to capture. Further, given the high degree of variability in self-regulation considered typical among preschool-age children, we questioned whether or not it would be possible to discriminate between such 
typical variability and atypical levels of dysregulation. Therefore, the primary questions investigated were

1. Can reliable dimensions of executive functions, as expressed in everyday behaviors, be defined adequately, and are there individual differences in these behaviors related to age group and sex?

2. What is the structure of the relation between these reliable dimensions in young children?

3. Can such dimensions differentiate between normal variability and executive dysfunction evident in children diagnosed with clinical disorders?

Specifically, we hypothesized that (a) a reliable set of behaviors could be assembled into a set of internally consistent scales tapping relevant executive functions; (b) the behaviors defining these scales of executive functions would be stable over time; (c) evidence for validity of these scales could be demonstrated via construct-based factor analysis, and; (d) the variability of the behaviors, as captured via rating-scale methodology, would permit sufficient differentiation between clinical and nonclinical populations. We present two related studies to examine these questions and stated hypotheses.

\section{STUDY 1: DEFINING BEHAVIORAL DOMAINS OF PRESCHOOL EXECUTIVE FUNCTION}

\section{Method}

Participants. Two samples of participants were used for this study. For initial scale development, ratings of children between the ages of 2 and 5 years were collected from 372 parents ( 196 boys, 176 girls; $M=3.6$ years, $S D=0.93$ ) from normative populations in the Midwest, mid-Atlantic, Northeast, and Southern regions of the United States. Children were recruited from numerous preschool programs and local health care facilities. Teachers for 201 of these children (102 boys, 99 girls; $M=3.6$ years, $S D=0.85$ ) also provided ratings. Data on children whose parents or teachers identified them as having any special education needs, as having attention, developmental, speech-language, or cognitive difficulties, or as prescribed psychotropic medications were not included in these analyses. Following scale refinement, a second sample from the same demographic regions and backgrounds was collected from 88 parents (50 boys, 38 girls) and 101 teachers ( 62 boys, 39 girls) for the purpose of replication. The two data sets - initial development and replication-combined represented a broad ethnic and socioeconomic status distribution in both the parent and teacher sam- 
ples. Tables 1 and 2 present the ethnic and socioeconomic distributions for the sample, respectively.

Instrumentation. The original pool of 129 items from the eight-scale BRIEF (Gioia et al., 2000) served as the basis for the development of a preschool version of the BRIEF. Many items were edited to reflect the larger preschool context of behavior, rather than a more limited set of school-related behaviors. For example, "homework" references were changed to "task" or "activity" references. A new set of items also was generated to reflect preschool-specific behaviors (e.g., "Plays carelessly or recklessly in situations where he/she could be hurt [e.g., playground equipment, swimming pool]."). Eliminating poorly worded, redundant, and irrelevant items resulted in a reduced pool of 97 items.

TABLE 1

Ethnic Distribution of Parent and Teacher Normative Samples

\begin{tabular}{|c|c|c|c|c|}
\hline \multirow[b]{2}{*}{ Ethnic Group } & \multicolumn{2}{|c|}{ Parent ${ }^{\mathrm{a}}$} & \multicolumn{2}{|c|}{ Teacher ${ }^{b}$} \\
\hline & $n$ & $\%$ & $n$ & $\%$ \\
\hline White & 336 & 73.0 & 217 & 71.9 \\
\hline African American & 64 & 13.9 & 37 & 12.3 \\
\hline Hispanic & 22 & 4.8 & 14 & 4.6 \\
\hline Asian and Pacific Islander & 14 & 3.0 & 6 & 2.0 \\
\hline Native American and Eskimo & 3 & 0.7 & 2 & 0.7 \\
\hline Not specified & 21 & 4.6 & 26 & 8.6 \\
\hline
\end{tabular}

${ }^{\mathrm{a}} \mathrm{N}=460 .{ }^{\mathrm{b}} \mathrm{N}=302$.

TABLE 2

Parent and Teacher Normative Samples by SES

\begin{tabular}{lrrrrr}
\hline & \multicolumn{3}{c}{ Paren $^{\mathrm{a}}$} & & \multicolumn{2}{c}{ Teacher $^{\mathrm{b}}$} \\
\cline { 2 - 3 } \cline { 5 - 6 } SES Classification & $n$ & $\%$ & & $n$ & $\%$ \\
\hline Upper & 87 & 18.9 & 71 & 23.5 \\
Upper middle & 133 & 28.9 & & 88 & 29.1 \\
Middle middle & 121 & 26.3 & 73 & 24.2 \\
Lower middle & 72 & 15.7 & 37 & 12.3 \\
Lower & 46 & 10.0 & 20 & 6.6 \\
Unassigned & 1 & 0.2 & 13 & 4.3 \\
\hline
\end{tabular}

Note. SES calculated via Hollingshead Index (Hollingshead, 1975). SES $=$ socioeconomic status. ${ }^{\mathrm{a}} N=460 .{ }^{\mathrm{b}} \mathrm{N}=302$. 


\section{Results}

Scale refinement. Individual item distributions were examined and items with high means and wide dispersion indexes were eliminated. Member scales then were examined via iterative item-total correlations. Items with low correlations $(<.40)$ were poor contributors and were removed from the scales. Finally, principal factor analysis with orthogonal rotation was used to clarify scale structure. The convergence of results prompted the removal of two of the scales included in the original BRIEF, Initiate and Monitor, and the combination of the Organization of Materials and the Plan/Organize scales. The initial scale-development process thus yielded a single 63 -item rating form for both parent and teacher or day care provider raters. Five executive domains emerged: Inhibit (16 items), Shift (10 items), Emotional Control (10 items), Working Memory (17 items), and Plan/Organize (10 items).

For the purpose of independent replication, additional data were collected from a second sample of parents $(N=88)$ and teachers $(N=101)$ as described previously, using the refined 63 -item scale. For the purpose of comparison, mean scores for each of the five executive domains defined by the 63 -item scale were calculated from the original 97-item scale, using the same items as in the 63 -item scale and compared to the mean scores from the 63 -item scale. Multivariate analysis of variance (MANOVA) revealed no significant differences (all $p s>.10, \eta^{2}<.02$ ) in mean ratings for any of the five executive domains between the initial ( 97 -item form) and replication (63-item form) samples, for either the parent or teacher raters. Therefore, the data from both samples were combined for subsequent analyses. Table 3 presents representative items within each scale for the combined parent and teacher samples, along with item-total correlations. Scale means by sex for the combined samples of 460 parent ratings and 302 teacher-caregiver ratings are depicted in Table 4. Mean item responses with a possible range of 1 to 3 were used for each scale to maintain the same metric across scales. Of note are the relatively low means for each scale, with small standard deviations, consistent with reasonable, but not excessive, normal variability. This variability is particularly relevant to Study 2 , where the differentiation between clinical and normative samples is investigated.

Internal consistency. Cronbach's alphas (1951) for parent ratings on the preschool BRIEF scales and total score were as follows: Inhibit $\alpha=.90$, Shift $\alpha=$ .85 , Emotional Control $\alpha=.86$, Working Memory $\alpha=.88$, Plan/Organize $\alpha=.80$, and total score $\alpha=.95$. Cronbach's alphas for teacher ratings were Inhibit $\alpha=.94$, Shift $\alpha=.90$, Emotional Control $\alpha=.91$, Working Memory $\alpha=.94$, Plan/Organize $\alpha=.97$, and total score $\alpha=.97$. Interestingly, parental ratings of Plan/Organize behaviors were somewhat lower than the rest of the scales. Overall, these results are consistent with excellent internal consistency. 
TABLE 3

Sample Items and Item-Total Correlations by Scale for Parent and Teacher Ratings

\begin{tabular}{|c|c|c|}
\hline \multirow[b]{2}{*}{ Scale } & \multicolumn{2}{|c|}{$\begin{array}{l}\text { Item-Total } \\
\text { Correlations }\end{array}$} \\
\hline & Parent $t^{\mathrm{a}}$ & Teacher $^{\mathrm{b}}$ \\
\hline \multicolumn{3}{|l|}{ Inhibit } \\
\hline Is unaware of how his or her behavior affects or bothers others & .51 & .71 \\
\hline Is impulsive & .61 & .70 \\
\hline Has trouble putting the brakes on his or her actions even after being asked & 66 & .75 \\
\hline \multicolumn{3}{|l|}{ Shift } \\
\hline Becomes upset with new situations & .61 & .59 \\
\hline Is upset by a change in plans or routines & .57 & .75 \\
\hline Has trouble "joining in" at unfamiliar social events & 62 & .66 \\
\hline \multicolumn{3}{|l|}{ Emotional control } \\
\hline Becomes upset too easily & .67 & .78 \\
\hline Mood changes frequently & .65 & .74 \\
\hline Small events trigger big reactions & .67 & .74 \\
\hline \multicolumn{3}{|l|}{ Working memory } \\
\hline When given two things to do, remembers only the first or last & .44 & .71 \\
\hline Has trouble concentrating on games, puzzles, or play activities & .58 & .74 \\
\hline Has trouble with activities or tasks that have more than one step & 60 & .75 \\
\hline \multicolumn{3}{|l|}{ Plan and organize } \\
\hline $\begin{array}{l}\text { When instructed to clean up, puts things away in a disorganized, random } \\
\text { way }\end{array}$ & .44 & .60 \\
\hline $\begin{array}{l}\text { Has trouble thinking of a different way to solve a problem or complete an } \\
\text { activity when stuck }\end{array}$ & .45 & .68 \\
\hline $\begin{array}{l}\text { Gets caught up in the small details of a task or situation and misses the } \\
\text { main idea }\end{array}$ & .41 & .56 \\
\hline
\end{tabular}

${ }^{\mathrm{a}} \mathrm{N}=460 .{ }^{\mathrm{b}} \mathrm{N}=302$.

TABLE 4

Scale Means and Standard Deviations by Sex for Parent and Teacher Ratings

\begin{tabular}{|c|c|c|c|c|c|c|c|c|}
\hline \multirow[b]{3}{*}{ Scale } & \multicolumn{4}{|c|}{ Parent Ratings ${ }^{\mathrm{a}}$} & \multicolumn{4}{|c|}{ Teacher Ratings ${ }^{\mathrm{b}}$} \\
\hline & \multicolumn{2}{|c|}{ Boys } & \multicolumn{2}{|c|}{ Girls } & \multicolumn{2}{|c|}{ Boys } & \multicolumn{2}{|c|}{ Girls } \\
\hline & $M$ & $S D$ & $M$ & $S D$ & $M$ & $S D$ & $M$ & $S D$ \\
\hline Inhibit & 1.53 & .36 & 1.43 & .33 & 1.45 & .43 & 1.25 & .30 \\
\hline Shift & 1.46 & .41 & 1.43 & .35 & 1.40 & .41 & 1.33 & .35 \\
\hline Emotional control & 1.51 & .37 & 1.56 & .40 & 1.38 & .41 & 1.36 & .41 \\
\hline Working memory & 1.38 & .30 & 1.34 & .29 & 1.34 & .37 & 1.23 & .34 \\
\hline Plan and organize & 1.52 & .32 & 1.51 & .34 & 1.38 & .35 & 1.29 & .33 \\
\hline
\end{tabular}

${ }^{\mathrm{a}} N=460,{ }^{\mathrm{b}} \mathrm{N}=302$. 
Temporal stability. Pearson correlations were calculated to examine the temporal stability of the preschool BRIEF in a sample of parent ratings $(n=52)$ over an average interval of 4.5 weeks (range 1-9 weeks). Correlations were Inhibit $r=.90$, Shift $r=.88$, Emotional Control $r=.87$, Working Memory $r=.85$, Plan/Organize $r$ $=.78$, and total score $r=.90$. Similarly, a sample of teachers $(n=67)$ completed test and retest forms over an average of 4.2 weeks (range 2-6 weeks), with correlations of Inhibit $r=.94$, Shift $r=.65$, Emotional Control $r=.83$, Working Memory $r$ $=.88$, Plan/Organize $r=.85$, and total score $r=.88$. Again, the temporal stability of parental ratings of Plan/Organize behaviors was somewhat lower than the rest of the scales, whereas teachers rated shifting behavior as somewhat less stable. These results are consistent with appropriate temporal stability.

Influence of child sex and age group. The means presented in Table 4 were examined for sex and age differences in the parent and teacher rater samples. Results of a 2 (boys, girls) by 4 (2-, 3-, 4-, and 5-year-olds) MANOVA for the parent sample revealed small, but significant, main effects of sex, $F(5,451)=5.65, p<$ $.001, \eta^{2}=.06$, and of age, $F(15,1349)=1.90, p<.02, \eta^{2}=.02$. Similarly, main effects of sex, $F(5,293)=5.86, p<.001, \eta^{2}=.09$, and of age, $F(15,875)=1.66, p<$ $.05, \eta^{2}=.03$, also were evident in the teacher rater sample. In both rater samples, the interaction of age by sex was not significant. Examination of the univariate analyses in the parent sample revealed only one small difference between boys and girls on the Inhibit scale, $\eta^{2}=.02$, with boys rated as having somewhat poorer inhibitory control than girls. In the teacher sample, boys similarly were rated as having greater inhibitory difficulties than girls, $\eta^{2}=.06$, but also were rated as having poorer Working Memory, $\eta^{2}=.02$, and Plan/Organize abilities, $\eta^{2}=.01$. For parent ratings, small but significant differences between age groups were found on the Inhibit, $\eta^{2}=.02$, Emotional Control, $\eta^{2}=.02$, and Plan/Organize, $\eta^{2}=.01$ scales, with 3 -year-olds rated as having uniquely more difficulty in these domains in comparison to 2-, 4-, and 5-year-olds. Similarly, for teacher ratings, there were age-related differences on the Shift, $\eta^{2}=.03$, and Emotional Control, $\eta^{2}=.03$, scales, again with a slight elevation in problematic behavior in 3 -year-olds relative to the other age groups.

Defining the structure of preschool executive function dimensions. With the scales adequately defined, internally consistent, and temporally stable, we examined the internal structure of the five scales. That is, what are the relations between these five executive function dimensions, and do they reflect a single overarching dimension, or are they better conceptualized as overlapping dimensions or shared common factors? Defining the structural relations between the five executive function scales speaks to the validity of the construct. Evidence of this validity based on the internal structure of the preschool BRIEF is a complex issue because of the nature of the executive functions as higher order, "supervisory" functions. 
Pragmatically, though, the executive problem-solving process argues for multiple executive processes to achieve multistep performance. Therefore, exploratory factor analyses with both the parent and teacher rater samples were conducted to investigate the preschool BRIEF scale structure.

To examine the underlying construct of the modified BRIEF as a measure of executive function in preschoolers, the exploratory factor analyses were conducted on the parent $(N=460)$ and teacher $(N=302)$ samples. Principal factor analysis was used as the exploratory method, with an oblique rotation (Promax) due to the likelihood of correlated factors. Decision criteria for the selection of an appropriate number of factors were based on conceptual and statistical considerations (Carroll, 1993). Our a priori conceptual model views executive function as a multidimensional construct (Miyake et al., 2000); therefore, a single factor model was not considered. Furthermore, a four-factor model was not considered because, with only 5 scales, one factor necessarily would be defined by only one scale. Analysis of the appropriate number of initial common factors was conducted by examining the eigenvalues, percentage of variance accounted for by the extracted factor, and scree plots (Gorsuch, 1983). The number of factors obtained was constrained to two or three primary factor solutions that were compared for interpretability of the differing factor structures. Subtests with factor loadings of $>.35$ were retained as measured indicators of the given factor.

For the parent sample, a three-factor model was retained as the best model in the analyses. Although only the eigenvalue for a one-factor model exceeded 1.0, the second and third factors accounted for $16 \%$ and $11 \%$ of the variance, respectively. In the two-factor solution, there was not sufficient separation among the scales for adequate interpretability. Furthermore, there was a Heywood case, where the communality for one variable (Emotional Control) exceeded 1.0 (Gorsuch, 1983). In Table 5 are the factor loadings for the three-factor solution, which accounted for $87 \%$ of the variance. Examination of the solution indicated that two scales, Working Memory and Plan/Organize, loaded exclusively on the first factor, with a secondary loading of the Inhibition scale. This factor was labeled Emergent Metacognition to reflect the developing metacognitive aspects of executive function in this age range. The Shift and Emotional Control scales defined a second factor, named Flexibility, capturing behavioral rigidity and emotional modulation. The Inhibit and Emotional Control scales defined a third factor Inhibitory Self-Control, reflecting the primary contribution of the Inhibit scale along with emotional modulation difficulties. The three factors were correlated moderately with values ranging from 0.46 to 0.66 .

The same principal factor analysis performed on the data from the teacher sample produced a three-factor solution similar to that in the parent sample, accounting for $92 \%$ of the variance. The factor loadings for this solution are presented in Table 5. Examination of the solution indicated that, again, the Working Memory and Plan/Organize scales loaded on the first factor, labeled Emergent Metacognition. 
TABLE 5

Factor Loadings for a Three-Factor Model for Parent and Teacher Ratings

\begin{tabular}{|c|c|c|c|c|c|c|}
\hline \multirow[b]{3}{*}{ Scale } & \multicolumn{3}{|c|}{ Parem Sample } & \multicolumn{3}{|c|}{ Teacher Sample ${ }^{\mathrm{b}}$} \\
\hline & \multicolumn{3}{|c|}{ Factor } & \multicolumn{3}{|c|}{ Factor } \\
\hline & 1 & 2 & 3 & 1 & 2 & 3 \\
\hline Working memory & .97 & & & .87 & & \\
\hline Plan and organize & .61 & & & .86 & & \\
\hline Shift & & .65 & & & .81 & \\
\hline Emotional control & & .37 & .63 & & .55 & .53 \\
\hline Inhibit & .39 & & .59 & & & .74 \\
\hline \multicolumn{7}{|l|}{ Factor correlations $(r)$} \\
\hline Factor 2 & .46 & & & .47 & & \\
\hline Factor 3 & .59 & .66 & & .55 & .66 & \\
\hline Cumulative $\%$ of variance & & $87 \%$ & & & $92 \%$ & \\
\hline
\end{tabular}

Note. Factor loadings greater than .35 are retained on a factor. Factor $1=$ emergent metacognition; Factor 2 = flexibility; Factor $3=$ inhibitory self-control.

${ }^{\mathrm{a}} \mathrm{N}=460 .{ }^{\mathrm{b}} \mathrm{N}=302$.

The Shift and Emotional Control scales again defined the second factor, named Flexibility. The Inhibit and Emotional Control scales again defined the third factor, labeled Inhibitory Self-Control. Similar to that with the parent rater sample, the factors were correlated moderately, ranging from 0.47 to 0.66 .

\section{Discussion}

These results suggest that dimensions of executive function that are consistent with current developmental theories can be defined adequately, coherently articulated, and consistently measured via parent and teacheror caregiver ratings of children's everyday behaviors. Further, there is preliminary evidence of construct validity based on exploratory factor analyses. The scale development processes resulted in modification of the original BRIEF for preschool-age children with a 63-item measure composed of five scales: Inhibit, Shift, Emotional Control, Working Memory, and Plan/Organize. Each of the scales demonstrated strong internal consistency and temporal stability. Thus, the behavioral and emotional regulation dimensions identified in older school-age children with the BRIEF also were evident in younger children using the resulting preschool modification of the BRIEF. In contrast, the more metacognitive scale dimensions were reduced from five in older school-age children to two in this younger group. In keeping with our pediatric neuropsychologist colleagues' views, behavioral inhibition, flexibility, and emotional regulation were adequately clear and measurable as reflected in the scale 
consistency indexes. The metacognitive aspects of executive functions appear to be less differentiated, or more intertwined, in young children. The scale development process yielded a broad Working Memory scale and a combined Plan/Organize scale; yet the more subtle domains of initiation and self-monitoring were not evident in this age range as independent scales. Overall, a reliable set of internally consistent scales that tap executive functions in a representative sample of preschool-age children were developed.

Age and sex differences were small but significant given the large sample sizes. Not surprisingly, boys were rated as having somewhat poorer inhibitory control and, in school settings, greater difficulty with working memory, planning, and organization. Three-year-old children were rated as having somewhat greater difficulties with self-regulation compared with 2-, 4-, and 5-year-old preschoolers, although the magnitude of these differences was small.

Exploratory factor analyses revealed that the relation between the five preschool executive function scales was represented best by the three common factors. The scales form three related factors: Inhibitory Self-Control, Flexibility, and Emergent Metacognition. Similar solutions were derived for the parent and teacher rating samples separately, further supporting the underlying structure across raters and respective settings. These findings provide evidence of validity based on the internal structure of the preschool BRIEF, consistent with the third hypothesis.

\section{STUDY 2: DIFFERENTIATION OF PRESCHOOL EXECUTIVE FUNCTIONS IN CLINICA AND NORMATIVE GROUPS}

With a preschool modification of the BRIEF adequately articulated and initially supported, we examined whether the scale was sufficiently sensitive to detect atypical variations in behavior in preschool-age children with clinically diagnosed disorders that might be expected to include deficits in executive function. We hypothesized that the variability in executive functions between clinical and normative populations could be captured via differences in parent and teacher ratings.

\section{Method}

Participants. Parent ratings for a mixed sample of 50 children between 2 and 5 years of age who were diagnosed clinically with either ADHD, an ASD, or a language disorder (excluding speech articulation disorders) were drawn from a larger pool of children referred for neuropsychological assessment. Teachers also completed ratings for a subset of the clinical sample $(N=20)$. Children in the clinical 
sample were matched individually with a nonreferred child from a local preschool based on the child's sex, age, and ethnicity and the mother's education level. A sample of children with varied diagnoses was used in this preliminary study to include children with a wide variety of executive disturbance. This procedure enabled initial examination of whether the preschool BRIEF was sensitive, but not specific, to individual differences in executive functions.

\section{Results}

Mean scores across all items within a scale (as opposed to scale sums), with a possible range of 1 to 3 for each scale, were calculated to facilitate comparisons across scales. In keeping with the results from the factor analyses conducted in Study 1, summary scores also were calculated for each of the Inhibitory Self-Control, Flexibility, and Emergent Metacognition factor-derived indexes. These summary scores were simple means across all items of the indexes' scales, again with a range of 1 to 3 . Figures 1 and 2 show the mean parent and teacher ratings, respectively, for clinical and control groups on the preschool BRIEF scales. Error bars indicate $1 S D$.

Parent sample. MANOVA with the control versus the clinical group as the between-subject factor and scales or indexes as dependent variables revealed significant group main effects and large effect sizes for all variables $\left(\eta^{2}\right.$ ranged from .16 to .43 ). Executive behaviors in the clinical group were rated consistently as more problematic than in the normative sample, across all domains assessed by the preschool BRIEF.

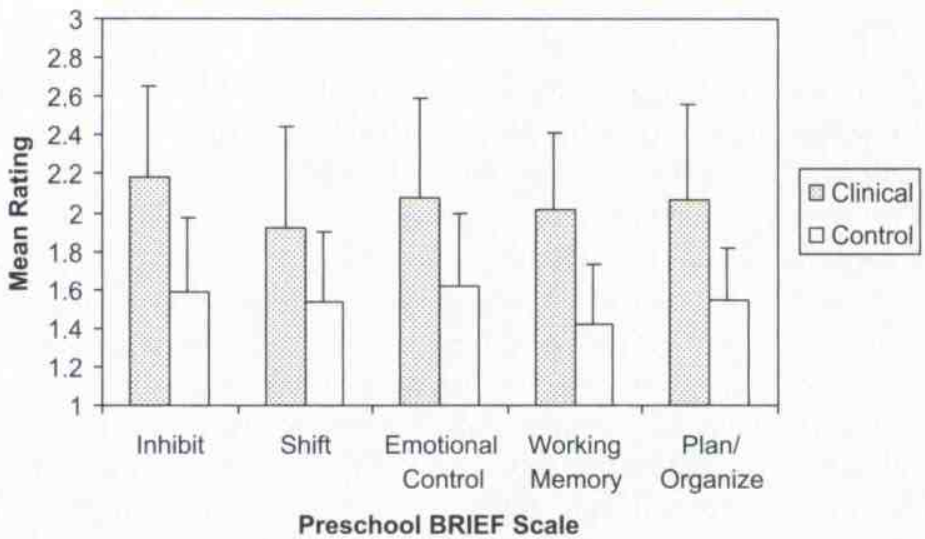

FIGURE 1 Mean parent ratings on BRIEF scales for clinical $(N=50)$ and matched control groups. 


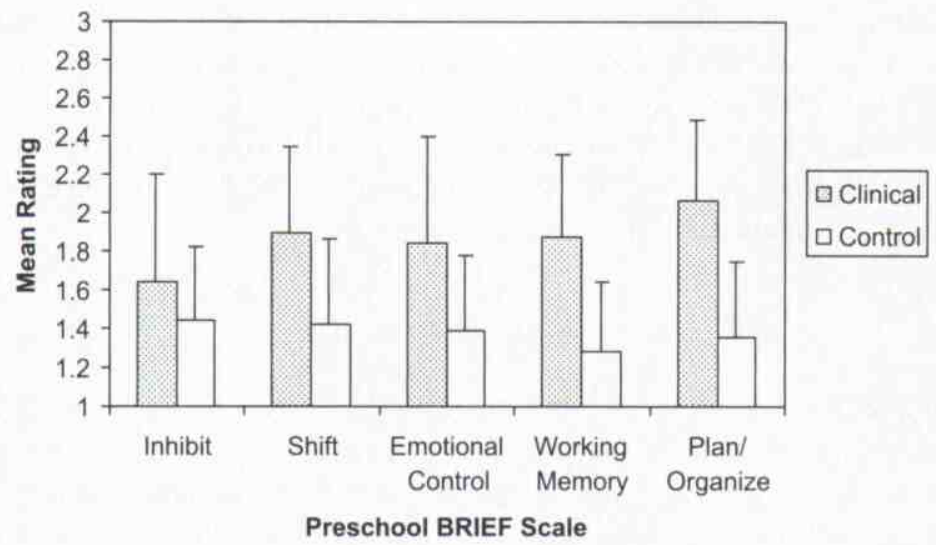

FIGURE 2 Mean teacher ratings on BRIEF scales for clinical $(N=20)$ and matched control groups.

Teacher sample. A similarly structured MANOVA revealed significant group main effects for all variables, except the Inhibit scale, with large effect sizes $\left(\eta^{2}\right.$ ranged from .19 to .44). Executive behavior in the clinical group was rated consistently as more problematic than in the normative control group in the majority of the preschool BRIEF domains assessed, with the exception of Inhibitory Control $\left(\eta^{2}=.05, n s\right)$.

\section{Discussion}

This preliminary examination of sensitivity of the modified BRIEF is limited in scope and generalizability by the small sample sizes and mixed diagnoses included in the clinical groups. Despite these limitations, there was sufficient variability in executive function behaviors between children diagnosed with clinical disorders and nonreferred typically developing children to detect group differences. Indeed, the effect sizes were moderate to large, suggesting that self-regulatory difficulties may be measured well via rating-scale methodology. Children with ADHD, ASD, or language disorders were rated by parents and teachers as having greater difficulty in most domains of executive function relative to matched peers. The differences in ratings were not accounted for by a child's age, sex, or ethnicity, or by parent education. Interpreted cautiously in light of the stated limitations, the study serves, however, as an initial test of the sensitivity of the modified BRIEF and as a pilot for future examination of profiles of executive function in preschoolers with specific clinical disorders. 


\section{CONCLUSIONS}

A complementary method of assessing the executive functions in preschool children via their everyday behavior as reported by their parents and teachers or day care providers was investigated. This literature on the ontogenetic aspects of executive function is relatively small, but growing, demonstrating that aspects of the executive functions likely are evident in infancy (Diamond, 1985; Haith et al., 1988), with continued development in the preschool period (Espy et al., 1999; Kochanska et al., 1997). Different disorders that may be evident in the preschool period may present with specific profiles of executive dysfunction (Diamond et al., 1997; Espy et al., 1999, 2003). Capturing the typical development of self-regulatory functions and atypical variations early in the course of development may prove useful in detecting difficulties and developing interventions during the critical years before elementary school entry. Assessment of executive functions in this age group is, however, challenging. Although executive functions can be measured via developmentally appropriate tasks, such as those adapted from developmental cognitive neuroscience (e.g., Espy et al., 1999, 2001), few such tasks are standardized, with known psychometric properties suitable for use by clinicians for individual, clinical assessment. These studies examined whether rating-scale methodology could reliably and consistently capture typical executive functions in preschool-age children, the internal structure of such executive function scales, and whether this method might be useful in detecting atypical executive functioning in children with developmental disorders.

In the first study, the existing executive function rating-scale measure, designed originally for school-age children and adolescents, was edited for use with preschool-age children. The scale development process yielded five scales reflecting subdomains of executive function consistent with the extant literature: Inhibitory Control, Flexibility, Emotional Modulation, Working Memory, and Planning/Organization. Finer gradations of metacognitive self-regulation, such as initiation and self-monitoring, were not internally consistent and could not be reliably defined as distinct subdomains. Multiple domains of executive function can be measured via parent and teacher ratings in a consistent and reliable manner, but they represent less differentiated, more intertwined abilities than what is observed in school-age children.

Furthermore, the overall scale structure and relations among the five scale dimensions revealed by exploratory factor analysis of parent and teacher ratings in the second study yielded similar three-factor solutions across raters: The Inhibit and Emotional Control scales formed an Inhibitory Self-Control factor, Shift and Emotional Control formed a Flexibility factor, and Working Memory and Plan/Organize formed an Emergent Metacognition factor. Interestingly, the Emotional Control dimension was associated comparably with both Inhibitory Control and Flexibility indexes, suggesting that the regulation of emotional response has gen- 
eral importance across a variety of executive domains and represents one of the key developmental tasks in this age range. The only difference among analyses conducted with the parent versus teacher rater samples was the contribution of the Inhibition scale. In the parent rater sample, Inhibition loaded both on the Emergent Metacognition and Inhibitory Control factors. Analysis of scale items revealed that several Inhibit Scale items contained referents to monitoring behavior relative to others or self. Given the less structured environment of the home setting in comparison to that of the school, these items may be related more prominently to emergent metacognitive skills in typically developing preschool children. That is, in the home, the child must use these emergent metacognitive skills to inhibit irrelevant or inappropriate behavior. In the school setting, the teacher and other authority figures may provide additional structure that, in turn, provides more explicit monitoring of behavior relative to peers. In preschool children with clinical disorders, where there is greater variability in behavior in the everyday context than in normative samples, the pattern of these relations among executive function scales and factors may differ.

Finally, the second study explored whether atypical variations in executive functions could be measured via a rating scale by comparing parent and teacher ratings of clinical versus nonclinical groups of matched children. In these samples, parents and teachers rated the clinical group of children as having more problematic executive behavior than the typically developing children across most domains measured. Interestingly, teachers did not rate behaviors measured by the Inhibit scale of children with mixed clinical disorders as differing from those of typically developing controls. The discrepancy from parental ratings may reflect the higher degree of structure in preschool classrooms that may limit the expression of disinhibition in that setting. Alternatively, these discrepant results across raters may be related to the small sample size of children with mixed diagnoses. Nevertheless, preliminary evidence that measurement of group differences is possible via rating-scale methodology was demonstrated.

In essence, the adaptation of the original BRIEF everyday behavior rating methodology to the measurement of executive behavior of preschoolers yielded an internally consistent, temporally stable instrument, with an internal structure consistent with the multidomain construct of executive functioning in preschool-age children (Espy et al., 1999; Hughes, 1998) that was sensitive to atypical variations in executive function development. Several general observations are relevant. The specificity of measurable executive function domains appears less differentiated in preschool-age children than in school-age children. Although the BRIEF assesses eight domains of executive functioning in older school-age children, this modification for preschool-age children resulted in a reduced set of five, more general, domains. Furthermore, there was greater cross-loading of the executive function scales on the factors in preschool children in comparison to that of older, school-age children (Gioia \& Isquith, in 
press). Consistent with our hypotheses, the metacognitive domains of self-regulation were more difficult to uniquely measure in this age group. In this manner, these findings from rating-scale methodology parallel those of the general developmental literature: Fundamental executive functions, such as inhibition and working memory, develop earlier, whereas more complex functions involved in problem solving and planning, have a more protracted course (Espy et al., 2001). An alternative explanation for the reduced number of metacognitive domains is that overt molar behavioral rating methods are not sensitive in capturing these processes in young children.

These findings document a range of variability in behaviors thought to reflect executive functions, where the variability is constrained sufficiently to enable atypical performance to be captured adequately. It also is important to note that the preschool BRIEF ratings are not anchored behaviorally in an absolute scaling sense, but instead tap parents' and teachers' own expectations for typical development, and their internal norms by querying the degree to which certain behaviors are problematic. In this sense, the degree of latitude that parents and teachers allow for the more variable preschool behavior is captured in the ratings, as well as the child's actual executive behavior. Nonetheless, the rating-scale methodology allows for a systematic and reliable capture of children's everyday executive function and dysfunction in preschool-age children.

Reliable reports of the preschool child's everyday behavioral manifestations of executive dysfunction have the potential for a high degree of ecological validity in understanding their real-world abilities. On the other hand, this method also carries limitations, as the focus is on a more global view of executive function in the everyday context with less process-specific information. This behavioral rating methodology is viewed best as a tool that is complementary to developmentally appropriate cognitive performance tests that measure the specific executive function processes. Furthermore, rating-scale methods depend on informant ratings and, therefore, may be affected by rater biases, including atypical developmental expectations of behavior by parents or teachers. The inclusion of validity scales, as are incorporated in the BRIEF for school-age children and adolescents, can address some of these problems, at least in their extreme form. The clinical judgment of the clinician also remains paramount in identifying possible bias in the context of individualized clinical assessment.

The derived preschool modification of the BRIEF was sensitive to variations in executive dysfunction among clinically referred and typically developing children, despite the small group sizes and mixed diagnostic etiologies. The purpose of these current analyses was not to uncover unique patterns of executive dysfunction in children with specific neurodevelopmental disorders, for example, which could be used for diagnostic and other clinical purposes. Rather, the preschool BRIEF scale should be viewed as capturing and describing broad domains of executive function in the everyday context that are sensitive to individ- 
ual differences in behavior. Further study with more specific diagnostic groups and larger sample sizes is warranted.

\section{ACKNOWLEDGMENTS}

We maintain financial interest in the BRIEF as developers of that instrument. No financial support was provided for any phase of this research. The publisher of the BRIEF did not have any input into this study and has not reviewed the manuscript.

We are grateful to Dennis L. Molfese and the reviewers for their helpful guidance in developing this article.

\section{REFERENCES}

Carroll, J. B. (1993). Human cognitive abilities: A survey of factor-analytic studies. New York: Cambridge University Press.

Cronbach, L. J. (1951). Coefficient alpha and the internal structure of tests. Psychometrika, 16, 297-334.

Denckla, M. B. (1994). Measurement of executive function. In G. R. Lyon (Ed.), Frames of reference for the assessment of learning disabilities: New views on measurement issues ( $\mathrm{pp} .117-142$ ). Baltimore: Brookes.

Diamond, A. (1985). Development of the ability to use recall to guide action, as indicated by infants' performance on AB. Child Development, 56, 868-883.

Diamond, A. (1990). Developmental time course in human infants and infant monkeys, and the neural bases of inhibitory control in reaching. Annals of the New York Academy of Sciences, 608. 637-676.

Diamond, A., Prevor, M. B., Callendar, G., \& Druin, D. P. (1997). Prefrontal cortex cognitive deficits in children treated early and continuously for PKU. Monographs of the Society for Research in Child Development, 62(4, Serial No. 252).

Espy, K., Stalets, M., McDiarmid, M., Senn, T., Cwik, M., \& Hamby, A. (2003). Executive functions in low risk preschoolers born preterm: Application of cognitive neuroscience paradigms. Child Neuropsychology, 8, 83-92.

Espy, K. A. (1997). The Shape School: Assessing executive function in preschool children. Developmental Neuropsychology, 13, 495-499.

Espy, K. A., \& Kaufmann, P. M. (2002). Individual differences in the development of executive functions in children: Lessons from delayed response and a-not-B tasks. In D. L. Molfese \& V. Molfese (Eds.), Developmental variations in learning: Applications to social, executive function, language and reading skills (pp. 113-137). Mahwah, NJ: Lawrence Erlbaum Associates, Inc.

Espy, K. A., Kaufmann, P. M., \& Glisky, M. L. (1999). Neuropsychologic outcome in toddlers exposed to cocaine in utero: a preliminary study. Developmental Neuropsychology, 15, 447-460.

Espy, K. A., Kaufmann, P. M, McDiarmid, M., \& Glisky, M. L. (1999). Executive functioning in preschool children: a-not-B and other delayed response format task performance. Brain and Cognition, 41. 178-199. 
Espy, K. A., Kaufmann, P. M., McDiarmid, M. D., \& Glisky, M. L. (2001). New procedures to assess executive functions in preschool children. Clinical Neuropsychologist, 15, 46-58.

Ewing-Cobbs, L., Prasad, M. R., Landry, S. H., Kramer, L., \& DeLeon, R. (2004/this issue). Executive functions following traumatic brain injury in young children. Developmental Neuropsychology, 26, $487-512$.

Fletcher, J. M., Francis, D. J., Stuebing, K. K., Shaywitz, B. A., Shaywitz, S. E., Shankweiler, D. P. et al. (1996) Conceptual and methodological issues in construct definition. In G. R. Lyon \& N. A. Krasnegor (Eds.), Attention, memory and executive function (pp. 17-42). Baltimore: Brookes.

Gioia, G. A., \& Isquith, P. K. (in press). Assessment of executive function in traumatic brain injury from an ecological perspective. Developmental Neuropsychology.

Gioia, G. A., Isquith, P. K., Guy, S. C., \& Kenworthy, L. (2000). The Behavior Rating Inventory of Executive Function. Lutz, FL: Psychological Assessment Resources.

Gioia, G. A., Isquith, P. K., Kenworthy, L., \& Barton, R. (2002). Profiles of everyday executive function in acquired and developmental disorders. Child Neuropsychology, 8, 121-137.

Gorsuch, R. L. (1983). Factor analysis (2nd ed.). Mahwah, NJ: Lawrence Erlbaum Associates, Inc.

Grodzinsky, G., \& Diamond, R. (1992). Frontal lobe functioning in boys with attention deficit hyperactivity disorder. Developmental Neuropsychology, 8, 427-445.

Haith, M. M., Hazan, C., \& Goodman, G. S. (1988). Expectation and anticipation of dynamic visual events by 3.5-month-old babies. Child Development, 59, 467-479.

Hollingshead, A. B. (1975). Four factor index of social status. New Haven, CT: Yale University Press.

Hughes, C. (1998). Finding your marbles: Does preschoolers' strategic behavior predict later understanding of mind? Developmental Psychology, 34, 1326-1339.

Kochanska, G, Murray, K., \& Coy, K. (1997). Inhibitory control as a contributor to conscience in childhood: From toddler to early school age. Child Development, 68, 263-277.

Korkman, M., Kirk, U., \& Kemp, S. (1998). NEPSY: a developmental neuropsychological assessment mamual. San Antonio, TX: Psychological Corporation.

McEvoy, R. E., Rogers, S. J., \& Pennington, B. F. (1993). Executive function and social communicative deficits in young autistic children. Journal of Child Psychology and Psychiatry, 34, 563-578.

Miyake, A., Friedman, N. P., Emerson, M. J., Witzki, A. H., Howerter, A., \& Wagner, T. D. (2000). The unity and diversity of executive functions and their contributions to complex "frontal lobe" tasks: a latent variable analysis. Cognitive Psychology, 41, 49-100.

Ozonoff, S., \& Jensen, J. (1999). Brief report: Specific executive function profiles in three neurodevelopmental disorders. Journal of Autism and Developmental Disorders, 29. $171-177$.

Passler, M. A., Isaac, W., \& Hynd, G. W. (1985). Neuropsychological development of behavior attributed to frontal lobe functioning in children. Developmental Neuropsychology, 1, 349-370.

Pennington, B. F., \& Ozonoff, S. (1996). Executive functions and developmental psychopathology. Journal of Child Psychology and Psychiatry and Allied Disciplines, 37, 51-87.

Ruff, H. A., \& Rothbart, M. K. (1996). Aftention in early development: Themes and variations. New York: Oxford University Press.

Sergeant, J. A., Guerts, H., \& Oosterlaan, J. (2002). How specific is a deficit of executive functioning for attention-deficit/hyperactivity disorder? Behavioural Brain Research, 130, 3-28.

Silver, C. (2000). Ecological validity in neuropsychological assessment in childhood traumatic brain injury. Journal of Head Trauma Rehabilitation, 15, 973-988.

Vaughn, B. E., Kopp, C. B., \& Krakow, J. B. (1984). The emergence and consolidation of self-control from eighteen to thirty months of age: Normative trends and individual differences. Child Development, 55, 990-1004.

Wellman, H. M. (1988). The early development of memory strategies. In F. E. Weinert \& M. Perlmutter (Eds.), Memory development: Universal changes and individual differences (pp. 3-29). Hillsdale, NJ: Lawrence Erlbaum Associates, Inc. 
Welsh, M. C., Pennington, B. F., \& Grossier, D. B. (1991). a normative-developmental study of executive function: a window on prefrontal function in children. Developmental Neuropsychology, 7 , 131-149. 
Copyright of Developmental Neuropsychology is the property of Lawrence Erlbaum Associates and its content may not be copied or emailed to multiple sites or posted to a listserv without the copyright holder's express written permission. However, users may print, download, or email articles for individual use. 